\title{
Otimização da síntese de nanopartículas de prata visando aplicação em sistemas biológicos
}

\author{
Keijok, W.J. ${ }^{1}$, Milaneze B.A. ${ }^{1}$, Oliveira J.P. ${ }^{1}$, Prado A.R. ${ }^{2}$, Bartochevis J.A.B. ${ }^{1}$, Pontes \\ M.J. ${ }^{2}$, Ribeiro M.R.N. ${ }^{2}$, Nogueira B.V. ${ }^{1}$, Guimarães M.C.C. ${ }^{1}$ \\ ${ }^{1}$ Laboratório de Ultraestrutura Celular Carlos Alberto Redins, Dep.Morfologia, CCS / UFES, Vitória - ES, Brasil \\ ${ }^{2}$ Laboratório de Telecomunicações, Dep. Engenharia Elétrica, CT / UFES, Vitória - ES, Brasil
}

\begin{abstract}
Resumo
O presente trabalho apresenta uma otimização da síntese de nanopartículas de prata e sua estabilidade coloidal, visando aplicabilidade em sistemas biológicos. Nesse trabalho foi explorada a síntese por redução química das nanopartículas avaliando razão molar entre os reagentes, tempo de síntese e concentração de estabilizantes. Técnicas de microscopia eletrônica e espectroscopia foram utilizadas para caracterização do material sintetizado. Os resultados foram promissores, indicando a possibilidade de utilizar este material para várias aplicações no meio biológico.
\end{abstract}

Palavras chaves: nanopartículas de prata, nanotecnologia, microscopia eletrônica de transmissão.

\section{Introdução}

Os nanomateriais como as nanopartículas metálicas, são de extrema importância no campo da nanotecnologia devido às suas propriedades físicas e químicas, com vantagem na interação com biomoléculas que faz prever inúmeras aplicações a nível biotecnológico [1].

Para que possam ser eficientemente utilizados em aplicações tecnológicas e biomédicas, os materiais nanoestruturados, como as nanopartículas de prata (AgNP's) devem ser capazes de se manterem estáveis por longos períodos de tempo, sem que haja perda de suas propriedades, ou modificações estruturais. Dessa maneira, a busca por novos métodos de síntese ou funcionalização voltados para aumentar a estabilidade química das nanopartículas tem se tornado objeto de estudo de vários pesquisadores [2-5]

As atividades biológicas das nanopartículas coloidais são influenciadas pela dimensão das partículas, por causa da sua maior área de superfície específica, de tamanho menor e a forma esférica. As AgNP's podem anexar à superfície da membrana celular e perturbar as suas funções, como permeabilidade e respiração [3].

A rota química adotada para a síntese das NP's obedece a uma série de parâmetros e o tipo de rota adotado tem como objetivo dar à possibilidade de controle sobre os componentes estruturais de materiais e dispositivos em escalas de tamanhos bem inferiores àquelas convencionais. A utilização das nanopartículas tem uma alta relação superfície / volume, resultando em uma alta reatividade e à necessidade de estabilização [4-5].
O objetivo deste trabalho foi otimizar a síntese de nanopartículas metálicas estáveis utilizando a redução química, bem como caracterizar os nanomateriais sintetizados.

\section{Materiais e Métodos}

Neste trabalho foram avaliadas três das variáveis que interferem no tamanho e concentração das nanopartículas, sendo elas a razão molar entre os reagentes, o tempo de síntese e a presença do estabilizante álcool polivinílico (PVA). Para verificar o efeito das variáveis sobre a conversão da reação, bem como encontrar as condições que maximizassem a síntese das nanopartículas, um planejamento experimental fatorial $\left(3^{3}\right)$ com 3 níveis e 3 variáveis foi realizado. O agente redutor utilizado foi o citrato de sódio ( $\mathrm{Na}_{3} \mathrm{C}_{6} \mathrm{H}_{5} \mathrm{O}_{7}$, Merk), o polímero para avaliar a estabilização foi o (PVA, Vetec) e a solução precursora, 0 nitrato de prata $\left(\mathrm{AgNO}_{3}\right.$, Merk). As variáveis avaliadas foram: Razão molar entre os reagentes (4:1, $4: 2$ e 4:3), tempo de síntese (5, 10 e $15 \mathrm{~min})$ e concentração do estabilizante $(0,200 \mu \mathrm{l}$ e $400 \mu \mathrm{l})$. Amostras de nanopartículas de prata (AgNP's) foram recolhidas após a etapa de síntese e as suas propriedades ópticas foram avaliadas por espectrofotometria no UV - vis (Evolution 300, Thermo). O tamanho e a morfologia das nanopartículas de prata foram examinadas por Microscópio Eletrônico de Transmissão (TEM 1400-JEOL), Microscópio Eletrônico de Varredura (SEM, 1610LV - JEOL) e Microscópio de Força Atômica (Shimadzu, SPM-9600). 


\section{Resultados e Discussão}

A resposta óptica das nanopartículas metálicas sintetizadas com citrato de sódio apresentou picos bem definidos por volta dos $430 \mathrm{~nm}$, demonstrando que 0 tempo de síntese avaliado e as razões molares dos reagentes foram significativas no processo de síntese (figuras 1 e 2). Os gráficos de superfície de resposta também são apresentados, mostrando a influência das variáveis em função da absorbância a $430 \mathrm{~nm}$.

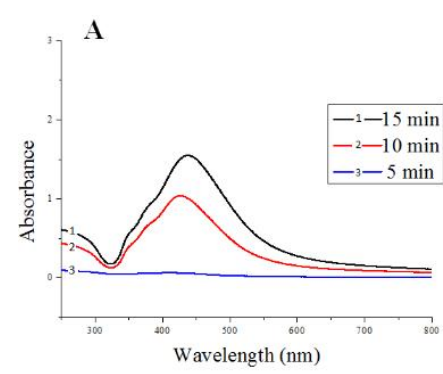

B

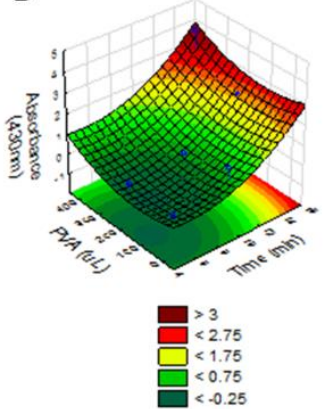

Figura 1. Espectro UV-Vis mostrando diferentes picos de absorbância nos tempos estudados (A); Gráfico de superfície resposta mostrando a influência das variáveis no processo de síntese a $430 \mathrm{~nm}$ (B).

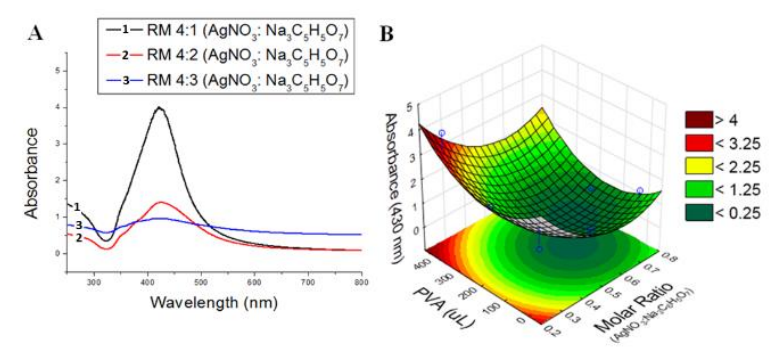

Figura 2. Espectro UV-Vis, mostrando diferentes picos de absorbância nas condições avaliadas de razões molares entre os reagentes $(A)$; Gráfico de superfície resposta mostrando a influência das variáveis no processo de síntese a $430 \mathrm{~nm}(B)$.

É possível verificar que AgNP's sintetizadas com citrato de sódio a 15 minutos mostrou maior absorbância (Figura 1A) e que as razões molares também foram significativas no processo de síntese, sendo que a razão molar 4:1 (nitrato de prata: citrato de sódio) apresentou o pico mais elevado (Figura 2 A), demonstrando maiores concentrações de nanopartículas sintetizadas.

A fim de caracterizar o diâmetro, a morfologia e a dispersão das nanopartículas de prata, na figura 3 são apresentadas as imagens obtidas por microscopia eletrônica de transmissão (MET).
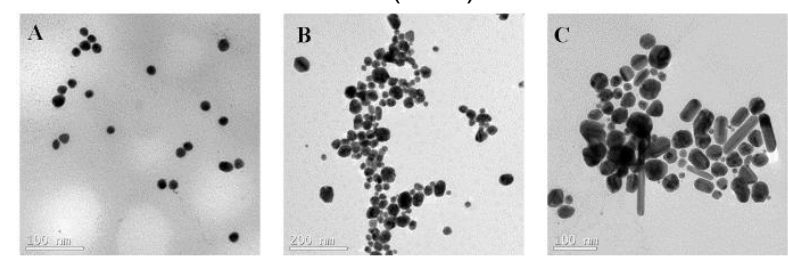

Figura 3. Imagens de AgNP's no tempo de síntese de 5 min (A) 10 min (B) e 15 min (C), utilizando microscópio eletrônico de transmissão.
Na Figura 3 é possível observar as AgNP's em fase de crescimento, é notável a diferença do tamanho das nanopartículas para os tempos de síntese avaliados. No tempo de 15 minutos verifica-se um diâmetro aproximado de 40 a $70 \mathrm{~nm}$, inclusive a presença de nanopartículas de vários formatos. Já no tempo inicial de 5 minutos as nanopartículas não passam dos 10 nanômetros e tem o formato predominantemente esférico.

$\mathrm{Na}$ figura 4, as imagens de microscopia eletrônica de varredura (MEV) e de força atômica (AFM) são apresentadas e mostram a dispersão dos nanomateriais em função do tempo de síntese avaliado, conforme é possível verificar abaixo:
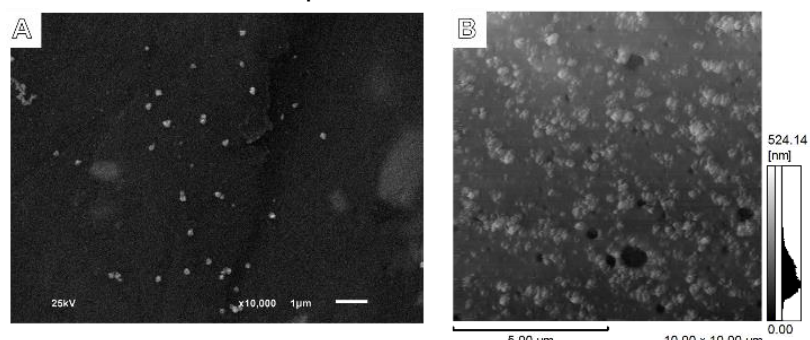

Figura 4. Imagens de nanopartículas de prata (MEV) tempo de síntese 5 min (A); Imagem de nanopartículas de prata (AFM), tempo de síntese $15 \min (B)$.

\section{Conclusões}

Uma rota de síntese de nanopartículas de prata foi otimizada, indicando que tanto o tempo como a razão molar entre os reagentes são significativos no processo de síntese. O álcool polivinílico (PVA) avaliado como estabilizante não obteve diferenças significativas, provavelmente pelo fato do agente redutor utilizado (citrato de sódio) já possuir atividade estabilizadora. Nanopartículas com diâmetros de aproximadamente 5 a $100 \mathrm{~nm}$ e absorção do sinal óptico em $430 \mathrm{~nm}$ foram sintetizadas. Novos trabalhos estão sendo realizados a fim de utilizar estes nanomateriais visando aplicação em sistemas biológicos, como biossensores e antibactericidas.

\section{Agradecimentos}

Ministério da Ciência e Tecnologia (MCTI / FINEP / CTINFRA PROINFRA 01/2006). Fundação de Amparo à Pesquisa do Espírito Santo (FAPES, 018/2012).

\section{Referências}

[1] Barrientos, A. G.; de la Fuente, J. M.; Rojas, T. C.; Fernandez, A.; Penadés, S. Chem. Eur. J. 2003, 9, 1909-1921.

[2] ASLAN, K.;PÉREZ-LUNA, V.H;Langmuir, v18, p.6059-6065, 2002.

[3] PAI, S.; TAK, Y. K; SONG, J. M. Applied And Environmental Microbiology v.73, n.6, p. 1712-1720, 2007.

[4] ZHAO, J. et al. Nanomedicine. 2006.

[5] MELO JR. M. A. et al. Química Nova, São Paulo, v. 35, p 1872-1878, 2012. 